\title{
Shock cardiogénico secundario a feocromocitoma
}

\section{Sr. Director:}

El feocromocitoma es un tumor secretor de catecolaminas cuyo origen histológico se encuentra en el tejido cromafín del sistema nervioso simpático. Suele formarse en la médula suprarrenal y raramente en otras localizaciones tales como ganglios simpáticos predominantemente abdominales. Las manifestaciones clínicas se deben fundamentalmente a la liberación de las catecolaminas, aparecen a cualquier edad pero con más frecuencia en jóvenes, y el signo clínico más habitual es la crisis hipertensiva (más del 50\% de los pacientes) asociado a palpitaciones, cefalea y diaforesis. Existen otras manifestaciones menos frecuentes pero potencialmente letales. A continuación describimos un caso de shock cardiogénico secundario a feocromocitoma.

Mujer de 21 años sin antecedentes de interés que ingresa en su hospital de referencia por presentar shock secundario a taquicardia ventricular monomorfa. Se procede a cardioversión, intubación orotraqueal y ventilación mecánica. En el electrocardiograma se observa descenso del ST en cara inferior y anterolateral. En la radiografía de tórax presenta infiltrado alveolar bilateral, y en la bioquímica sanguínea se aprecia elevación de los marcadores de lesión miocárdica (CPK $1.630 \mathrm{mU} / \mathrm{ml}, \mathrm{MB} 126 \mathrm{mU} / \mathrm{ml}$, LDH $1.147 \mathrm{mU} / \mathrm{ml})$.

$\mathrm{Al}$ ingreso en nuestra unidad presenta gran inestabilidad hemodinámica que requiere tratamiento con dobutamina: $8,6 \mu \mathrm{g} / \mathrm{kg} / \mathrm{min}$ y noradrenalina: $1,5 \mu \mathrm{g} /$ $\mathrm{kg} / \mathrm{min}$ para mantener una tensión arterial sistólica adecuada. Se realiza ecocardiograma transtorácico donde se observa hipoquinesia generalizada de predominio en segmentos basales y medios de todas las caras, con fracción de eyección del ventrículo izquierdo de $30-40 \%$, sin valvulopatías ni otras anomalías significativas. Se canaliza catéter de SwanGanz con los siguientes resultados: índice cardíaco $2,2 \mathrm{l} / \mathrm{min} / \mathrm{m}^{2}$ y presión de enclavamiento pulmonar 
$23 \mathrm{mmHg}$. En la coronariografía no se aprecian lesiones significativas.

Al cuarto día del ingreso se retira todo el soporte vasoactivo, presenta un índice cardíaco de $3,51 / \mathrm{min} / \mathrm{m}^{2}$ medido con el catéter de Swan-Ganz y mejoría de la función sistólica ventricular según ecocardiograma con fracción de eyección del ventrículo izquierdo superior al 55\%. En las siguientes 48 horas presenta picos de hipertensión arterial con aumento de la tensión arterial sistólica hasta 190-200 mmHg junto con disminución del índice cardíaco hasta 2,5 $1 / \mathrm{min} / \mathrm{m}^{2}$ y aumento del gradiente alveoloarterial de oxígeno. Estos episodios se repiten en los siguientes días pese al tratamiento antihipertensivo.

Se realizó determinación de catecolaminas en sangre con el siguiente resultado: noradrenalina L $31.687 \mathrm{pmol} / \mathrm{l}$, adrenalina L $7.527 \mathrm{pmol} / \mathrm{l}$. Se realiza tomografía axial computarizada abdominal en la que se aprecia una masa de $2,7 \mathrm{~cm}$ en glándula adrenal izquierda.

Dentro de las manifestaciones clínicas menos frecuentes del feocromocitoma se encuentran el alargamiento del intervalo QT y las arritmias tanto ventriculares como supraventriculares ${ }^{1}$. Así mismo están descritos escasos casos de shock cardiogénico con síntomas clínicos y pruebas complementarias compatibles con infarto agudo de miocardio pero sin alteraciones significativas en la coronariografía ${ }^{2}$ y reversión completa de la contractilidad miocárdica, como es el caso que hemos expuesto anteriormente. Se han planteado distintas hipótesis fisiopatológicas como son el vasoespasmo ${ }^{3}$ o la lesión directa miocárdica inducida por catecolaminas ${ }^{4}$. La importancia de este caso radica en que debe tenerse un alto grado de sospecha clínica en pacientes jóvenes que presentan shock cardiogénico secundario a infarto de miocardio no explicable por otros motivos, crisis hipertensiva y ausencia de lesiones en la coronariografía.

M. CRUZ-TEJEDOR, A. ESTEBAN, B. WAEZ

Y J. C. MARTÍN

Servicio de Medicina Intensiva. Hospital Clínico San Carlos. Madrid. España.

\section{BIBLIOGRAFÍA}

1. Cheng TO, Bashour TT. Striking electrocardiographic changes associated with pheochrocytoma. Chest. 1976;70:397-9.

2. Darzé E, Von Sostén R. Pheochromocytoma-induced segmental myocardial dysfunction mimicking an acute myocardial infarction in a patient with normal coronary arteries. Arq Bras Cardiol. 2004;82:178-80.

3. Sheikhzadeh A, Fatourechi V, Paydar D. Inusual cardiovascular manifestation in a case of pheochromocytoma. Clin Cardiol. 1983;6:136-42.

4. Nanda AS, Feldman A, Liang CS. Acute reversal of pheocromocytoma-induced catecholamine cardiomiopathy. Clin Cardiol. 1995;18:421-3. 